\title{
Coexistence and Adsorption Properties of Heavy Metals by Polypropylene Microplastics
}

\author{
Tingyu Fan, ${ }^{1,2,3}$ Jie Zhao,, ${ }^{1,3}$ Yingxiang Chen, ${ }^{1,3}$ Miao Wang, ${ }^{1,3}$ Xingming Wang $\mathbb{D}^{2,3}$ \\ Shun Wang, ${ }^{1,3}$ Xiaoyang Chen, ${ }^{1,3}$ Akang Lu, ${ }^{1,3}$ and Shijiao Zha ${ }^{1,3}$ \\ ${ }^{1}$ School of Earth and Environment, Anhui University of Science and Technology, Huainan 232001, China \\ ${ }^{2}$ State Key Laboratory of Simulation and Regulation of Water Cycle in River Basin, China Institute of Water Resources and \\ Hydropower Research, Beijing 100038, China \\ ${ }^{3}$ Anhui Engineering Laboratory for Comprehensive Utilization of Water and Soil Resources \& Ecological Protection in Mining Area \\ with High Groundwater Level, Huainan 232001, China
}

Correspondence should be addressed to Xingming Wang; xmwang-2004@126.com

Received 11 June 2021; Revised 4 September 2021; Accepted 9 September 2021; Published 14 October 2021

Academic Editor: Qiaohui Fan

Copyright (c) 2021 Tingyu Fan et al. This is an open access article distributed under the Creative Commons Attribution License, which permits unrestricted use, distribution, and reproduction in any medium, provided the original work is properly cited.

\begin{abstract}
Plastic particles with a diameter of $5 \mathrm{~mm}$ or less are called microplastics. Microplastics are one of the primary sources of pollution in the environment. It has been proven that microplastics are also carriers of heavy metals, but there are few studies on their adsorption mechanism. In this study, the adsorption of $\mathrm{Pb}, \mathrm{Cu}, \mathrm{Cd}$, and $\mathrm{Zn}$ by polypropylene (PP) microplastics was analyzed and discussed. The morphology of PP was observed by scanning electron microscopy (SEM), the surface elemental composition of PP was determined by X-ray photoelectron spectroscopy (XPS), and the functional groups of PP were analyzed by Fourier transform infrared spectroscopy (FTIR). The results showed that the adsorption behavior of microplastics to different heavy metals could be balanced in 32 hours. Kinetics experiments showed that the adsorption process could be fitted well by a two-stage dynamic model, and the adsorption of $\mathrm{Pb}$ and $\mathrm{Cu}$ by $\mathrm{PP}$ is greater than that of $\mathrm{Cd}$ and $\mathrm{Zn}$. The Freundlich model has the best fitting effect on $\mathrm{Pb}$ for the adsorption isothermal results. The Langmuir model showed that the process is favorable for adsorption. The adsorption of mixed heavy metals by microplastics showed that when the concentration of the mixed adsorption mass was low, the presence of a coexistence system promoted the adsorption of $\mathrm{Zn}$ and Cu by microplastics. With an increasing concentration, the adsorption of 4 heavy metals by microplastics is inhibited.
\end{abstract}

\section{Introduction}

At present, plastic has unconsciously entered all aspects of life, from industry to agriculture and from technology to human life [1-4]. Because of its low cost, lightweight, durability, and extensibility, plastics are widely used all worldwide $[5,6]$. The global consumption of plastics is estimated to reach 348 million tons in 2018 [7]. Although plastic products bring us much convenience, they can also enter into the environment and cause harm $[3,8,9]$. Plastic waste in the environment is decomposed into tiny plastics under physical and chemical actions. When the diameter of these plastics is no more than $5 \mathrm{~mm}$, they can be defined as microplastics [10-12]. For example, in mining areas, there are many microplastics and heavy metals in subsidence areas due to human activities or other factors [13], which have a great adverse impact on human, animal, and plant life. As a highly trophic organism, humans are one of the victims affected by pollution accumulating in the food chain, and we have begun to pay attention to microplastic pollution [13-15]. Therefore, it is imperative to study microplastics. Due to some properties of microplastics, such as physicochemical properties, surface properties, small particle size, large specific surface area, and hydrophobicity, they may adsorb other harmful pollutants in the surrounding environment, such as heavy metals $[16,17]$. And studies have shown, in addition to the direct impact of microplastics on organisms, they are also potential carriers of heavy metals due to their stubbornness and high specific surface area $[3,18,19]$. The first report on the amount of metals in microplastics appeared in early 
2010 at The Turner Laboratory [20], where the authors investigated the association between metals and plastic production particles in the Marine environment. Then, groundbreaking results by Holmes et al. [3] on metal adsorption on microplastics showed that the formation of biofilms on microplastics affects the adsorption of heavy metals. Since then, researchers have made the adsorption of heavy metals by microplastics more clear. Heavy metals generally refer to metals with a density greater than 4.5 grams per cubic centimeter. Heavy metals are persistent and toxic pollutants that are not easy to transfer and linger for a long time, causing serious harm to plants, animals, and even humans [4]. Heavy metals can be divided into two categories according to their toxic characteristics. One group is toxic at high concentrations but essential for plants and animals at low concentrations, including elements such as $\mathrm{Cu}, \mathrm{Zn}$, and $\mathrm{Fe}$. The other group is toxic to organisms even at low concentrations, endangering the health of animals and plants, including elements such as $\mathrm{Cd}, \mathrm{Pb}$, and $\mathrm{Hg}$ [21].

Until recently, despite the awareness that heavy metals [22-25] and microplastics [26-30] would cause ecological risks, their combined effects on heavy metals are still poorly known, especially when many heavy metals coexist. Previous studies have used microplastics to adsorb various heavy metals, respectively. For example, Mao et al. [31] studied the adsorption mechanism of polystyrene (PS) for heavy metals and the effect of aging on the adsorption of heavy metals. Purwiyanto et al. [32] investigated the adsorption of $\mathrm{Pb}$ and $\mathrm{Cu}$ in microplastics in the Musi River and the environment effect. Taking polyethylene terephthalate (PET) fragments as typical micro plastics, Wang et al. [33] used ultraviolet radiation to simulate the photoaging of microplastics in the environment in the laboratory and studied the adsorption of $\mathrm{Cu}^{2+}$ and $\mathrm{Zn}^{2+}$. And the results show that the adsorption capacity of aged microplastics for heavy metals is higher than that of original microplastics. However, there are few studies on the adsorption of microplastics in the environment of coexistence of heavy metals. And because heavy metals coexist in the actual environment, it is very necessary to simulate this coexistence environment to study microplastics and heavy metals. We selected several representative heavy metals $(\mathrm{Pb}, \mathrm{Zn}, \mathrm{Cu}$, and $\mathrm{Cd}$ ) to study their adsorption characteristics to microplastics to clarify the adsorption mechanism [15-17]. The adsorption kinetics and isothermal adsorption models were used to study the adsorption of heavy metals on microplastics. There are many kinds of microplastics on the market. We chose polypropylene (PP) as the research object because PP is one of the most widely used plastics and has good adsorption capacity $[34,35]$. Thus, we combined a model of heavy metal coexistence and adsorption to systematically simulate the real environment (coexistence of multiple heavy metals). The adsorption effect of different concentrations of metal and whether there is mutual promotion or inhibition between heavy metals were studied. This work can provide a theoretical basis for the normal environmental behavior of microplastics and their interactions with heavy metals.

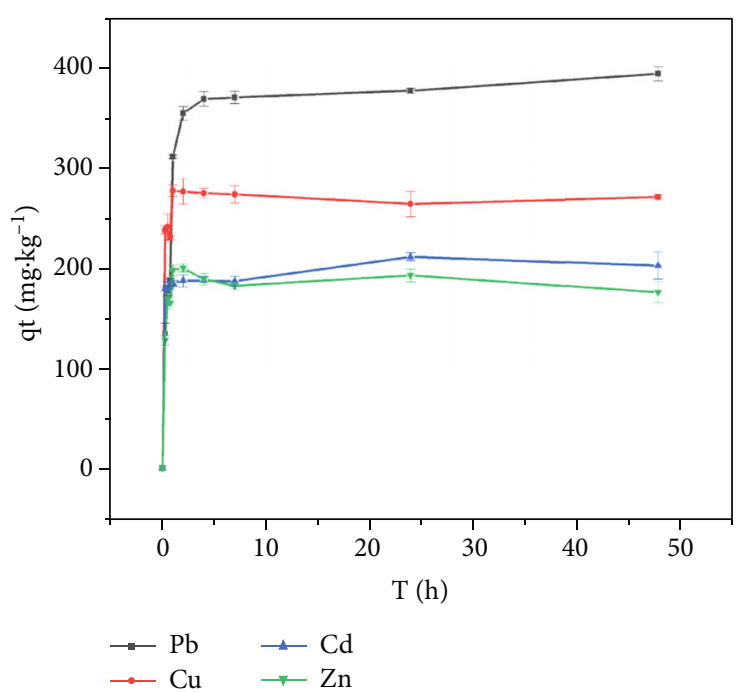

FIgURE 1: Adsorption curve of polypropylene microplastics $\left(C_{e}=0.7 \mathrm{mg} \cdot \mathrm{L}^{-1}, V=20 \mathrm{~mL} 4\right.$, temperature at $\left.298 \mathrm{~K}\right)$.

\section{Materials and Methods}

2.1. Materials and Characterization. Polypropylene (PP) was purchased from Sinopec Shanghai Chemical Co., Ltd. Lead $(\mathrm{Pb})$, zinc $(\mathrm{Zn})$, copper $(\mathrm{Cu})$, and cadmium $(\mathrm{Cd})$ standard solutions were purchased from National Nonferrous Metals and Electronic Materials Analysis and Testing Center. A crusher (800A) was purchased from Yongkang Azera Electric Appliance Co., Ltd. An atomic absorption spectrophotometer with specification A3 was purchased from Beijing General Instrument Co., Ltd. All analytically pure chemicals (anhydrous ethanol, hydrochloric acid, and potassium nitrate) for the adsorption experiments were purchased from Sinopharm Chemical Reagent Co., Ltd.

2.2. Sample Preparation. The purchased polypropylene plastic particles were crushed by the pulverizer, and then, the crushed plastic particles were passed through a 20-mesh sieve and kept in a beaker. Polypropylene is a hydrophobic substance, and ultrapure water and magnetic rotor were added to the beaker and stirred for 24 hours to wash it. Then, the samples were soaked in $10 \%$ hydrochloric acid $(\mathrm{HCl})$ for 48 hours. Finally, ultrapure water and ethanol were used for cleaning it, and any heavy metals were removed using an ultrasonic cleaner. After cleaning, the plastic was placed into an electric constant temperature drying oven at $50^{\circ} \mathrm{C}$ for 72 hours. After drying, the microplastics were sealed in a polyethylene bag [16].

\subsection{Adsorption Experiments and Data Analysis}

2.3.1. Adsorption Kinetics. The experiment was conducted and analyzed with a flame atomic absorption spectrophotometer. Two groups of basic solutions without heavy metals and two groups of PP were used as controls. Then, the adsorption capacity of PP for heavy metals was calculated by the concentration dependence between the two experiments $[36,37]$. 


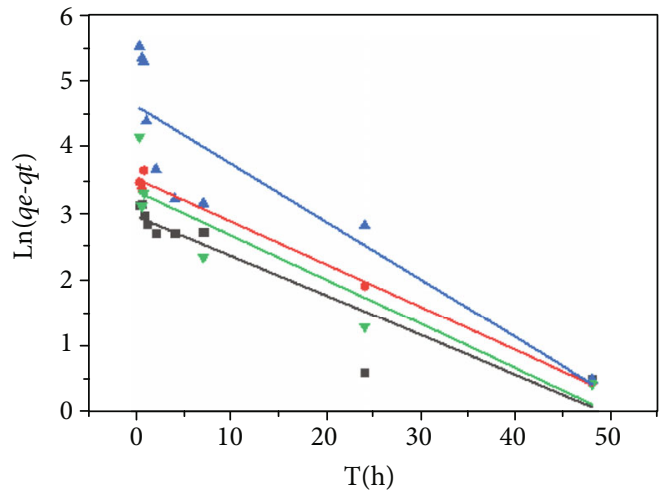

(a)

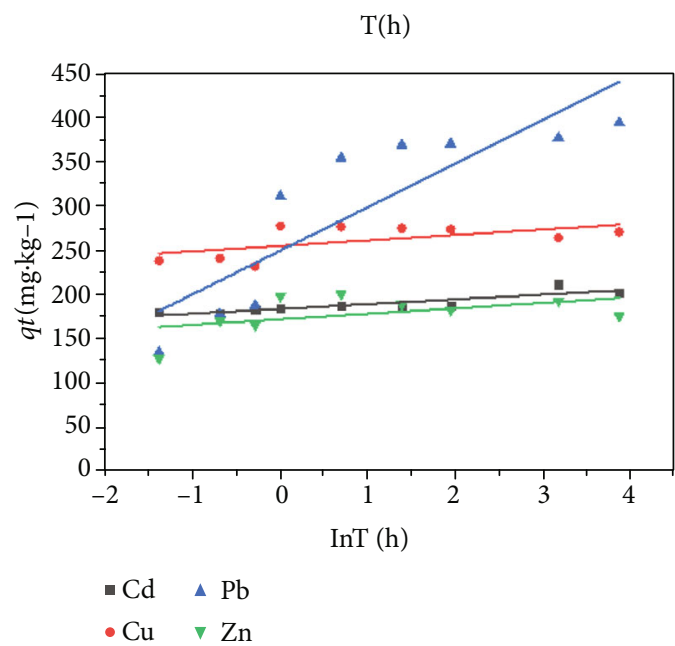

(c)

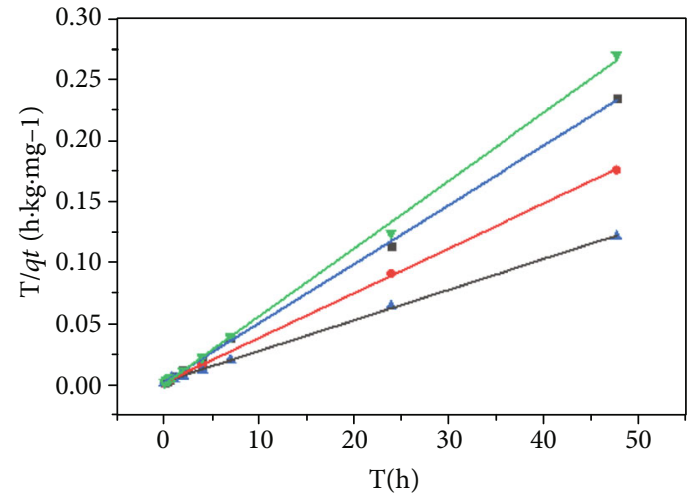

(b)

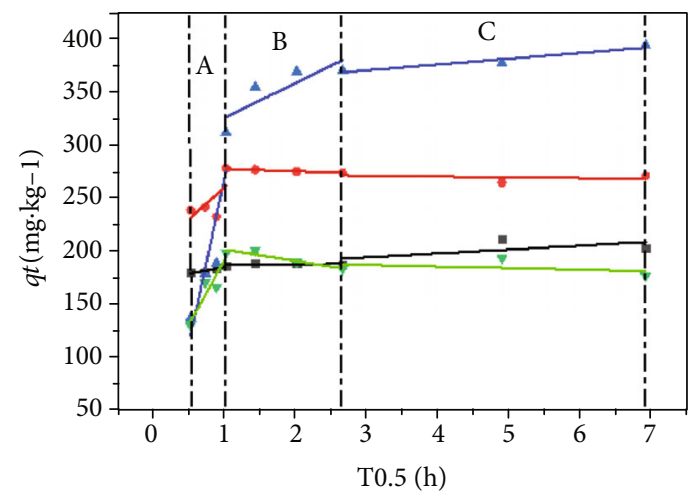

(d)

Figure 2: (a) First-order kinetics model, (b) second-order dynamic model, (c) Elovich model, and (d) intraparticle diffusion model $\left(C_{e}=0.7\right.$ $\mathrm{mg} \cdot \mathrm{L}^{-1}, V=20 \mathrm{~mL}$, temperature at $\left.298 \mathrm{~K}\right)$.

The adsorption kinetics of the four kinds of heavy metals in microplastics can be described by the first-order and second-order kinetics models. The formula of each model is as follows: (1) the first-order kinetics adsorption model, (2) the second-order kinetics adsorption model, (3) the Elovich model, and (4) the intraparticle diffusion model:

$$
\begin{aligned}
\lg \left(q_{e}-q_{t}\right) & =\lg q_{e}-k_{1} t, \\
\frac{t}{q_{t}} & =\frac{1}{K_{2} q_{e}^{2}}+\frac{t}{q_{e}}, \\
q_{t} & =\frac{1}{\beta} \ln (\alpha \cdot \beta)+\frac{t}{\beta} \ln t, \\
q_{\mathrm{t}} & =k_{\mathrm{dif}} t^{1 / 2}+C,
\end{aligned}
$$

where $q_{e}\left(\mathrm{mg} \cdot \mathrm{g}^{-1}\right)$ represents the adsorption amount at adsorption equilibrium, $q_{t}\left(\mathrm{mg} \cdot \mathrm{g}^{-1}\right)$ represents the adsorption capacity at time $t(\mathrm{~min}), K_{1}\left(\mathrm{mg} \cdot \mathrm{min} \cdot \mathrm{g}^{-1}\right)$ represents the adsorption reaction rate constant of the first-order kinetics adsorption model, $K_{2}\left(\mathrm{mg} \cdot \mathrm{min} \cdot \mathrm{g}^{-1}\right)$ is the adsorption reaction rate constant of the second-order kinetics adsorption model, $\alpha\left(\mathrm{mmol}^{-1} \cdot \mathrm{min}^{-1}\right)$ represents the initial adsorp- tion rate constant of the reaction in Elovich model, $\beta$ $\left(\mathrm{g} \cdot \mathrm{mmol}^{-1}\right)$ is the parameter related to the surface coverage degree of the adsorbent and the chemical adsorption activation energy, and $K_{\text {dif }}\left(\mathrm{mg} \cdot \mathrm{g}^{-1} \cdot \mathrm{min}^{-1 / 2}\right)$ is the intraparticle diffusion rate constant.

2.3.2. Adsorption Isotherm. A standard solution of heavy metals $(\mathrm{Pb}, \mathrm{Zn}, \mathrm{Cu}$, and $\mathrm{Cd})$ was used for this experiment. The determination method was the same as for the adsorption kinetics. follows:

The equation of Henry's model used in this study is as

$$
q_{e}=K_{H} C_{e},
$$

where $q_{e}\left(\mathrm{mg}^{-1}\right)$ represents the adsorption capacity of a unit adsorbate, $K_{H}\left({\left.\mathrm{~L} \cdot \mathrm{g}^{-1}\right)}^{-1}\right.$ represents Henry's coefficients, and $C_{e}\left(\mathrm{mg} \cdot \mathrm{L}^{-1}\right)$ represents the mass concentration of adsorbate in the liquid phase.

The adsorption process of $\mathrm{Pb}, \mathrm{Cu}$, and other heavy metals on the microplastics was simulated by a one-dimensional model (Freundlich and Langmuir models) [23, 38]. The 
TABLE 1: Fitting parameters of adsorption kinetics of heavy metals by microplastics.

\begin{tabular}{lcccccccrcr}
\hline Absorbate & \multicolumn{3}{c}{ First-order kinetic } & \multicolumn{3}{c}{ Second order dynamic } & \multicolumn{3}{c}{ Intraparticle diffusion } \\
$R^{2}$ \\
$\mathrm{~B}$
\end{tabular}

Freundlich model uses the assumption of a heterogeneous surface, and the equation is $[23,39-41]$

$$
\ln q_{e}=\ln K_{F}+\frac{1}{n} \ln C_{e}
$$

where $q_{e}\left(\mathrm{mg} \cdot \mathrm{L}^{-1}\right)$ represents the equilibrium adsorption capacity of adsorbate in the solid phase, $C_{e}\left(\mathrm{mg}^{-1} \mathrm{~g}^{-1}\right)$ represents the equilibrium concentration of the adsorbate in the liquid phase, $K_{F}\left(\mathrm{mg} \cdot \mathrm{g}^{-1}\right)$ is the partition coefficient of the Freundlich model and represents the adsorption capacity, and $n$ is dimensionless and represents the nonlinear degree of the adsorption isotherm model.

The Langmuir model assumes that adsorption takes place in a single layer and is uniform, and adsorption arises only once on each side [39]. The equation is

$$
\frac{1}{q_{e}}=\frac{1}{b q_{m}} \cdot \frac{1}{C_{e}}+\frac{1}{q_{m}},
$$

where $q_{m}\left(\mathrm{mg} \cdot \mathrm{g}^{-1}\right)$ represents the saturated adsorption capacity on the adsorbent and $b\left(\mathrm{~L} \cdot \mathrm{mg}^{-1}\right)$ represents the adsorption constant of the Langmuir model.

The linear equation of the Temkin model is [42]

$$
q_{e}=\frac{R T}{b_{T}} \ln C_{e}+\frac{R T}{b_{T}} \ln A_{T},
$$

where $B=R T / b_{T}, b_{T}\left(\mathrm{~J} \cdot \mathrm{mol}^{-1}\right)$ is the Temkin constant related to the heat of adsorption, $A_{T}\left(\mathrm{~L} \cdot \mathrm{mg}^{-1}\right)$ is the Temkin isotherm equilibrium binding constant, $R$ is the gas constant, and $T$ is the absolute temperature at $303 \mathrm{~K}$.

2.3.3. Coexistence of Adsorption. Microplastics can adsorb heavy metals, and organic pollutants due to their large specific surface area and hydrophobicity. Microplastics have different adsorption capacities when adsorbing different heavy metals. In the coexistence adsorption experiment, a standard solution of heavy metals $(\mathrm{Pb}, \mathrm{Zn}, \mathrm{Cu}$, and $\mathrm{Cd}$ ) was used for detection, and the determination method was performed with a flame atomic absorption spectrophotometer.

2.4. Material Characterization. Scanning electron microscopy (SEM) (Flexsem1000, Hitachi, Japan) was used to examine the morphology of PP. A small sample was fixed on a metal platform, and the sample surface was sprayed with platinum. The magnification of SEM was selected as 100 times, and the acceleration voltage was $15 \mathrm{kV}$. The func-
TABLE 2: Fitting parameters of Elovich model.

\begin{tabular}{lccc}
\hline Absorbate & $\alpha$ & $\beta$ & $R^{2}$ \\
\hline $\mathrm{Cd}$ & $3.4828 \times 10^{15}$ & 0.1845 & 0.7919 \\
$\mathrm{Cu}$ & $5.3942 \times 10^{18}$ & 0.1613 & 0.3535 \\
$\mathrm{~Pb}$ & $7.9035 \times 10^{3}$ & 0.0202 & 0.7466 \\
$\mathrm{Zn}$ & $8.2402 \times 10^{12}$ & 0.1615 & 0.2413 \\
\hline
\end{tabular}

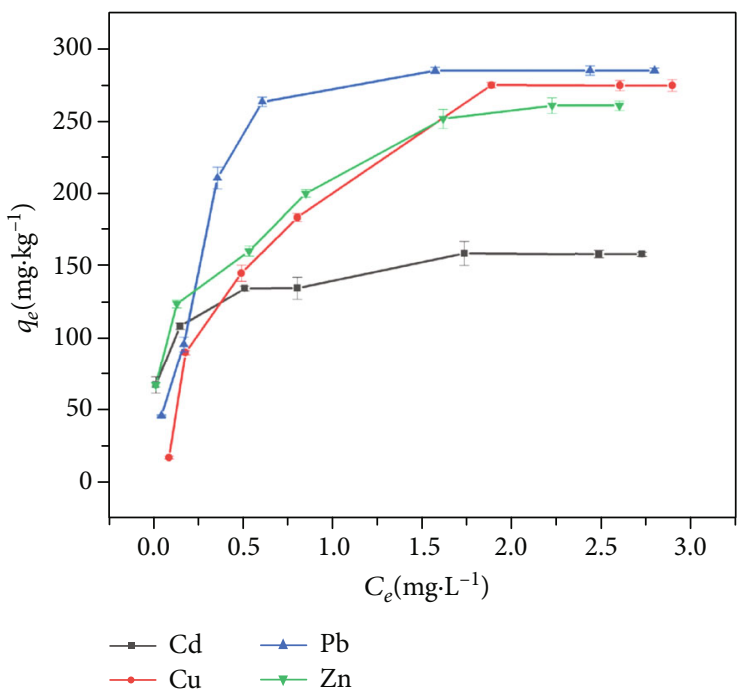

FIgURE 3: Adsorption isotherm on the original polypropylene $(V=20 \mathrm{~mL}$, temperature at $298 \mathrm{~K}, t=48 \mathrm{~h}$ ).

tional groups of PP were analyzed by Fourier transform infrared transmission (FTIR) spectroscopy (Nicolet IS50, Thermo Fisher Scientific, USA). After the interference light formed by the transmission and reflection of the light source penetrates the sample, the optical signal is processed by Fourier transform, and the infrared absorption spectrum of transmittance is obtained. The surface element composition of PP was determined by X-ray photoelectron spectroscopy (XPS) (Escalab 250XI, Thermo Fisher Scientific, USA) [43].

\section{Results and Discussion}

3.1. Adsorption Kinetics Analysis. To evaluate the effect of timing on the adsorption of heavy metals on PP, four kinds of heavy metals were selected to test the adsorption capacity of PP for heavy metals over different periods [31]. It can be 


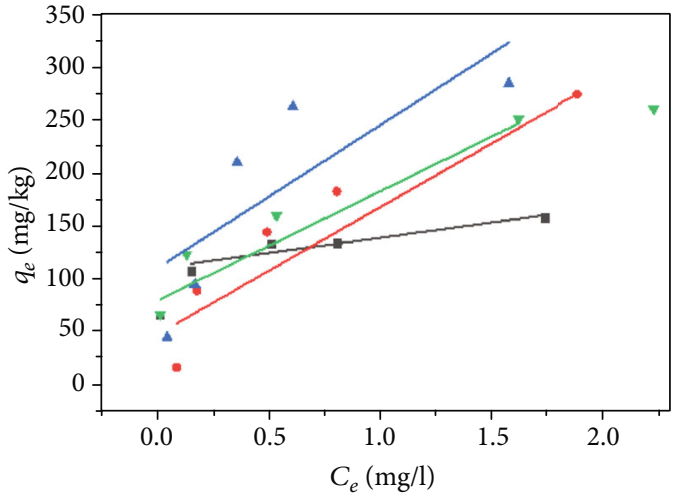

(a)

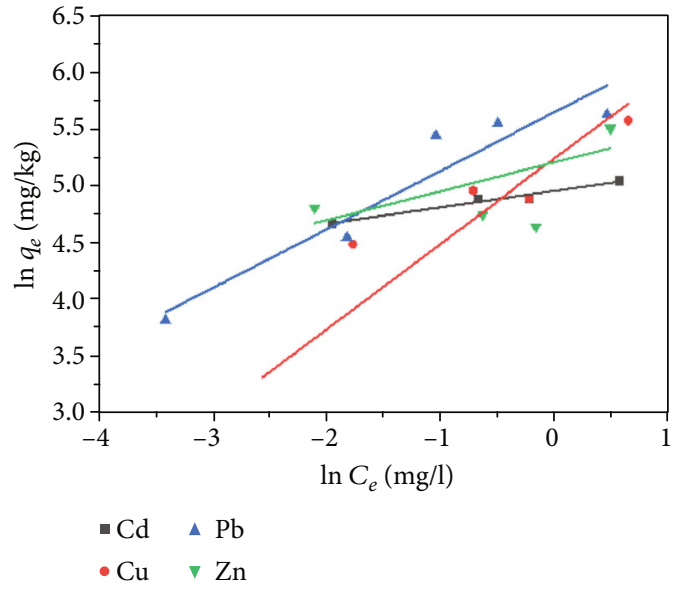

(c)

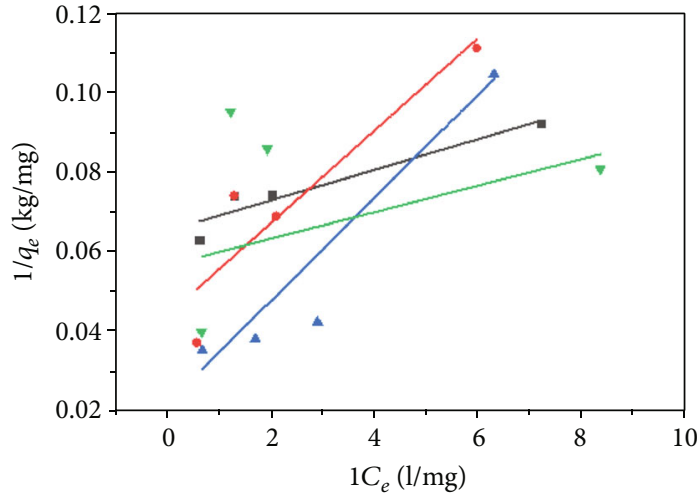

(b)

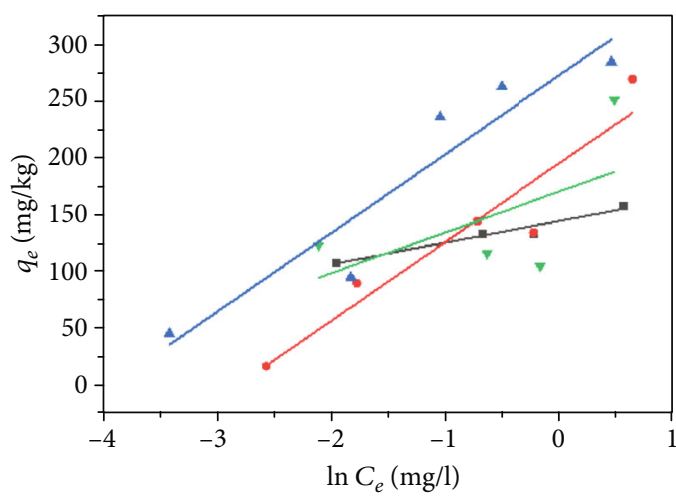

(d)

Figure 4: (a) Henry model, (b) Langmuir model, (c) Freundlich model, and (d) Temkin model ( $V=20 \mathrm{~mL}$, temperature at $298 \mathrm{~K}, t=48 \mathrm{~h}$ ).

TABLE 3: Regression parameters of Henry and Langmuir models for adsorption isotherms of heavy metals on microplastics.

\begin{tabular}{lccccc}
\hline \multirow{2}{*}{ Absorbate } & \multicolumn{2}{c}{ Henry model } & \multicolumn{3}{c}{ Langmuir model } \\
& $K_{H}$ & $R^{2}$ & $b$ & $q_{m}$ & $R^{2}$ \\
\hline $\mathrm{Cd}$ & 28.650 & 0.8971 & 0.002 & 152.672 & 0.9091 \\
$\mathrm{Cu}$ & 119.790 & 0.8924 & 3.836 & 224.719 & 0.8493 \\
$\mathrm{~Pb}$ & 134.798 & 0.5897 & 1.713 & 452.489 & 0.9820 \\
$\mathrm{Zn}$ & 102.993 & 0.9202 & 17.212 & 176.056 & 0.2983 \\
\hline
\end{tabular}

seen from the adsorption curve in Figure 1 that different heavy metals have different adsorption characteristics, and the order of adsorption capacity is $\mathrm{Pb}^{2+}>\mathrm{Cu}^{2+}>\mathrm{Cd}^{2+}>\mathrm{Zn}^{2+}$. The maximum adsorption capacity of $\mathrm{Pb}^{2+}$ was $395.62 \mathrm{mg} \cdot \mathrm{kg}^{-1}$, followed by $\mathrm{Cu}^{2+}\left(271.99 \mathrm{mg} \cdot \mathrm{kg}^{-1}\right)$ and $\mathrm{Cd}^{2+}\left(203.32 \mathrm{mg} \cdot \mathrm{kg}^{-1}\right)$, and the minimum adsorption capacity of $\mathrm{Zn}^{2+}$ was $193.73 \mathrm{mg} \cdot \mathrm{kg}^{-1}$. At the same time, the research results of Godoy et al. [44] showed that $\mathrm{Pb}$ is the heavy metal most readily adsorbed by microplastic polypropylene. In the adsorption process of this study, the adsorption was fast in the first 4 hours, was slow between 4 and 32 hours, and finally reached equilibrium. To further clarify the adsorption characteristics, we processed the data with origin 2018 and used a first-order kinetics model, second-
TABLE 4: Regression parameters of Freundlich and Temkin models for adsorption isotherms of heavy metals on microplastics.

\begin{tabular}{ccccccc}
\hline \multirow{2}{*}{ Absorbate } & \multicolumn{3}{c}{ Freundlich model } & \multicolumn{3}{c}{ Temkin model } \\
& $K_{F}$ & $n$ & $R^{2}$ & $R T / b_{T}$ & $A_{T}$ & $R^{2}$ \\
\hline $\mathrm{Cd}$ & 144.496 & 6.840 & 0.9672 & 19.074 & 2005.992 & 0.9569 \\
$\mathrm{Cu}$ & 194.340 & 1.318 & 0.8391 & 69.331 & 16.993 & 0.9039 \\
$\mathrm{~Pb}$ & 293.081 & 1.921 & 0.9066 & 69.372 & 52.118 & 0.8921 \\
$\mathrm{Zn}$ & 186.810 & 3.894 & 0.61048 & 35.919 & 114.544 & 0.3333 \\
\hline
\end{tabular}

order kinetics model, intraparticle diffusion model, and Elovich model to describe the adsorption capacity of lead $(\mathrm{Pb})$, zinc $(\mathrm{Zn})$, cadmium $(\mathrm{Cd})$, and copper $(\mathrm{Cu})$ on polypropylene microplastics.

Figures 2(a) and 2(b) show the first-order and secondorder kinetics fitting diagrams, respectively. The $R$-square of the first-order model is between 0.92 and 0.98 , and that of the second-order model is between 0.996 and 40.999, which indicates that the adsorption process of heavy metals by PP is more in line with a second-order kinetics model. When Lang et al. studied the adsorption of heavy metals on polystyrene microplastics, they also considered that the adsorption was more in line with a pseudo-second-order kinetics model than a first-order kinetics model [45]. 
Figure 2(d) shows the intraparticle diffusion model, which shows that the adsorption can be divided into three stages of $\mathrm{A}, \mathrm{B}$, and $\mathrm{C}$, and the adsorption occurs powerfully in stage $A$, then becomes milder in stage $B$ and by stage $C$; the adsorption almost stops and reaches the saturation state. Moreover, the linear graph does not pass through the origin, indicating that the adsorption process involves intraparticle diffusion, but is not unique. The kinetics fitting parameters are shown in Tables 1 and 2 .

In this study, the concentration of adsorbate was constant, and PP had a greater specific surface area and more micropores, which led to more adsorption sites on the surface of $\mathrm{PP}$, and the corresponding maximum adsorption capacity was larger. However, the adsorption capacity for $\mathrm{Pb}$ and $\mathrm{Cu}$ was stronger.

3.2. Adsorption Isotherm Analysis. Figure 3 shows the adsorption isotherms of four heavy metals on the original PP. It can be seen from the isotherm diagram that each heavy metal has a different adsorption capacity. In the initial stage, $q_{e}$ increased rapidly with increasing adsorbent concentration. When the adsorbent concentration increases to a certain degree, $q_{e}$ increases slowly and gradually tends to become stable. At the same time, it can be seen from the $q_{e}$ and the slope of the image when the microplastic polypropylene tends to be stable that the adsorption amount of heavy metals $\mathrm{Pb}$ and $\mathrm{Cu}$ is greater than that of $\mathrm{Cd}$ and $\mathrm{Zn}$, which is consistent with the results of the adsorption kinetics experiment.

To better study the adsorption characteristics of heavy metals, we used the Henry, Langmuir, Freundlich, and Temkin models to fit them $[46,47]$, as shown in Figures 4(a)4(d), and the regression parameters are listed in Tables 3 and 4 . From the fitting results, we can see that the Freundlich model has the best fitting effect for the heavy metals $\mathrm{Pb}, \mathrm{Cu}, \mathrm{Cd}$, and $\mathrm{Zn}$, where $n$ is greater than 1 ; it shows that PP adsorption of heavy metals is multilayer adsorption, and the adsorption is favorable. Fasfous et al. studied tetrabromobisphenol. An adsorption experiment on multiwalled carbon nanotubes, also showed that the adsorption is favorable when $n$ is between 1 and 10 [48, 49].

According to the above research, Tables 3 and 4 show that the Freundlich coefficient $\left(K_{F}\right)$ of heavy metal adsorption by microplastics meets the order of $\mathrm{Pb}^{2+}>\mathrm{Cu}^{2+}>\mathrm{Zn}^{2+}>-$ $\mathrm{Cd}^{2+}$. The maximum adsorption capacity of $\mathrm{Pb}^{2+}$ was $452.489 \mathrm{mg} \cdot \mathrm{kg}^{-1}$, the maximum adsorption capacity of $\mathrm{Cd}^{2+}$ was $152.672 \mathrm{mg} \cdot \mathrm{kg}^{-1}, \mathrm{Cu}^{2+}$ was $224.719 \mathrm{mg} \cdot \mathrm{kg}^{-1}$, and $\mathrm{Zn}^{2+}$ was $176.056 \mathrm{mg} \cdot \mathrm{kg}^{-1}$. The results also show that among the four heavy metals, PP has the highest adsorption affinity for $\mathrm{Pb}^{2+}, \mathrm{Cu}^{2+}$, and $\mathrm{Zn}^{2+}$ which have similar affinities, and PP has the lowest affinity for $\mathrm{Cd}^{2+}$.

3.3. Coexistence Adsorption. The above studies show that polypropylene microplastics have different adsorption capacities for lead, zinc, copper, and cadmium. Obviously, it can be seen that the maximum adsorption capacity of $\mathrm{Pb}$ is higher than that of the other heavy metals. To describe the adsorption characteristics of each heavy metal more clearly, we used Origin 2018 to draw Figures 5 and 6 to show

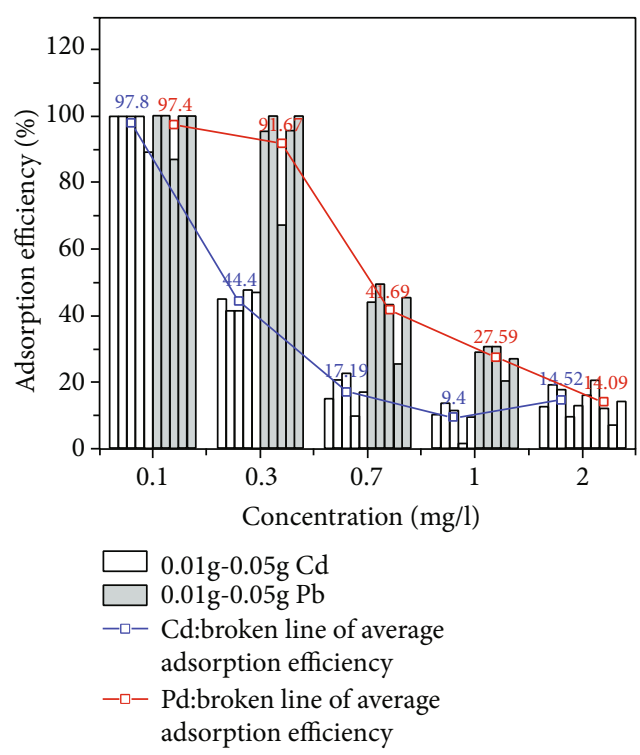

Figure 5: Adsorption efficiency of microplastics to Cadmium (Cd) and lead $(\mathrm{Pb})(V=20 \mathrm{~mL}$, temperature at $298 \mathrm{~K}, t=48 \mathrm{~h})$.

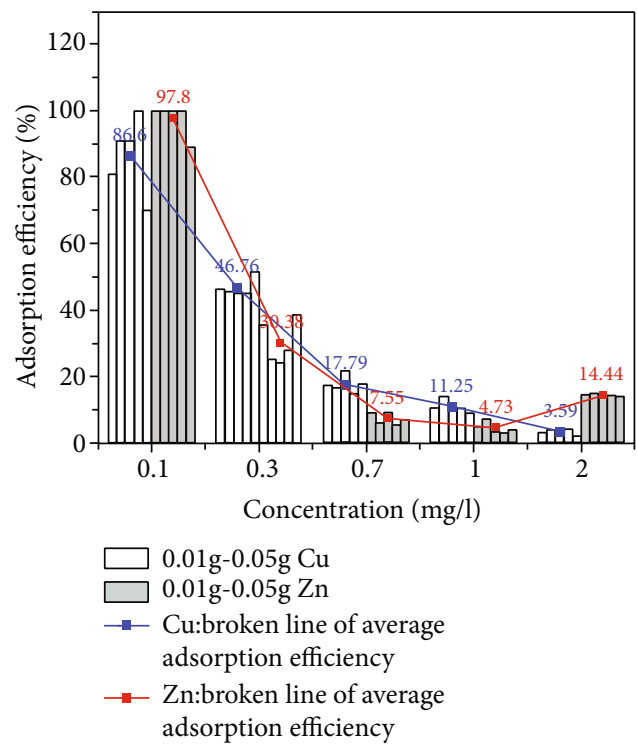

FIgURE 6: Adsorption efficiency of microplastics to copper $(\mathrm{Cu})$ and Zinc $(\mathrm{Zn})(V=20 \mathrm{~mL}$, temperature at $298 \mathrm{~K}, t=48 \mathrm{~h})$.

the adsorption efficiency of the four heavy metals under coexisting adsorption. Figure 5 shows the adsorption efficiency of $\mathrm{Cd}$ and $\mathrm{Pb}$, and Figure 6 shows the adsorption efficiency of $\mathrm{Cu}$ and $\mathrm{Zn}$.

As we can see from Figures 5 and 6, the adsorption efficiency of microplastics for $\mathrm{Pb}, \mathrm{Cu}, \mathrm{Zn}$, and $\mathrm{Cd}$ is the highest when the concentration of mixed adsorbent is $0.1 \mathrm{mg} / \mathrm{L}$, and the adsorption efficiency of heavy metals all slows down with the increase of adsorbate concentration. Accordingly, when the concentration of adsorbate is low, the adsorption effect of microplastics on 4 kinds of heavy metals can almost be regarded as saturated state, and with the increase of the concentration of mixed adsorbents, the removal effect was 


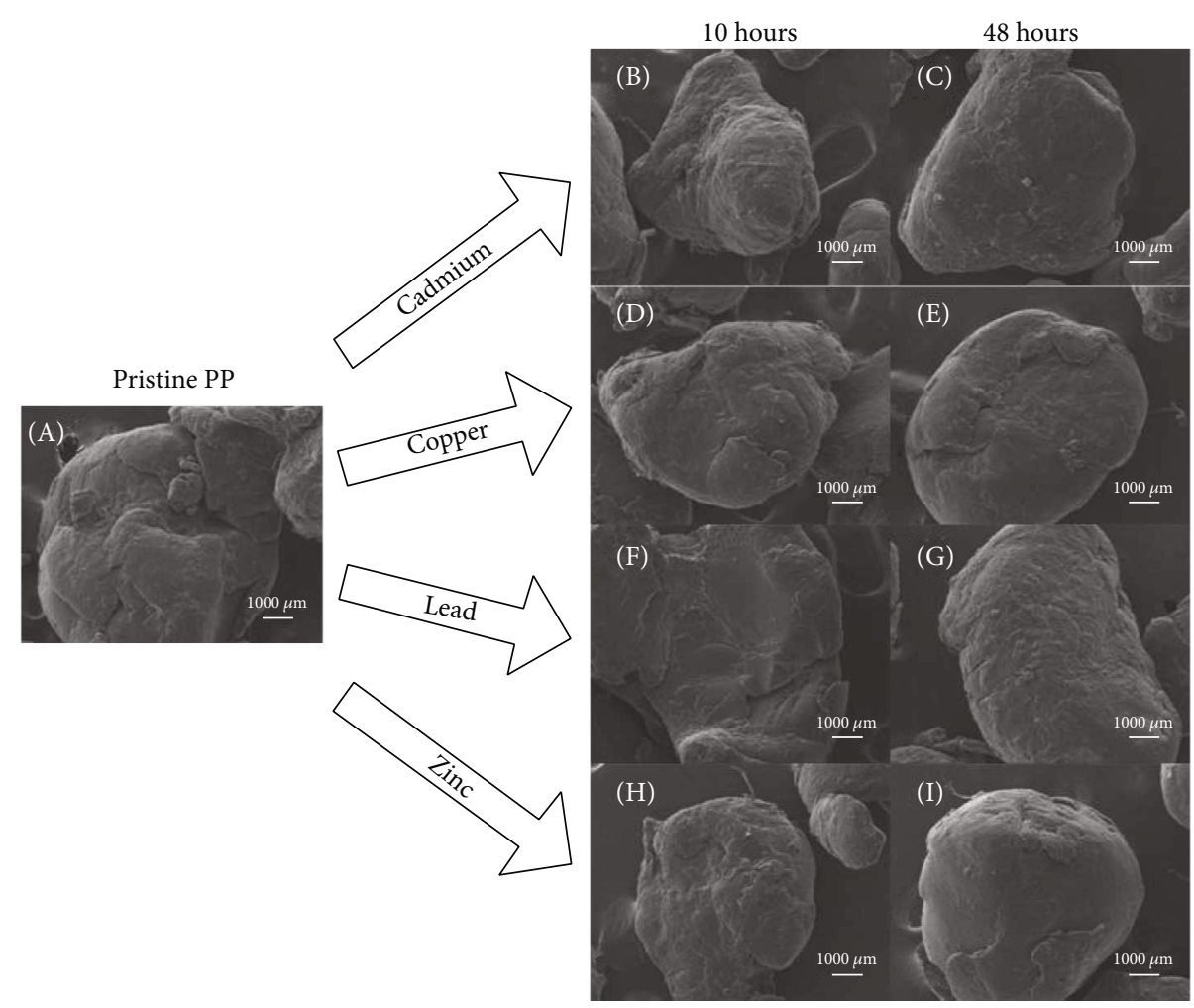

FIGURE 7: Scanning electron microscopy of polypropylene adsorption of different heavy metals $\left(C_{e}=0.7 \mathrm{mg} \cdot \mathrm{L}^{-1}, V=20 \mathrm{~mL}\right.$, temperature at $298 \mathrm{~K})$.

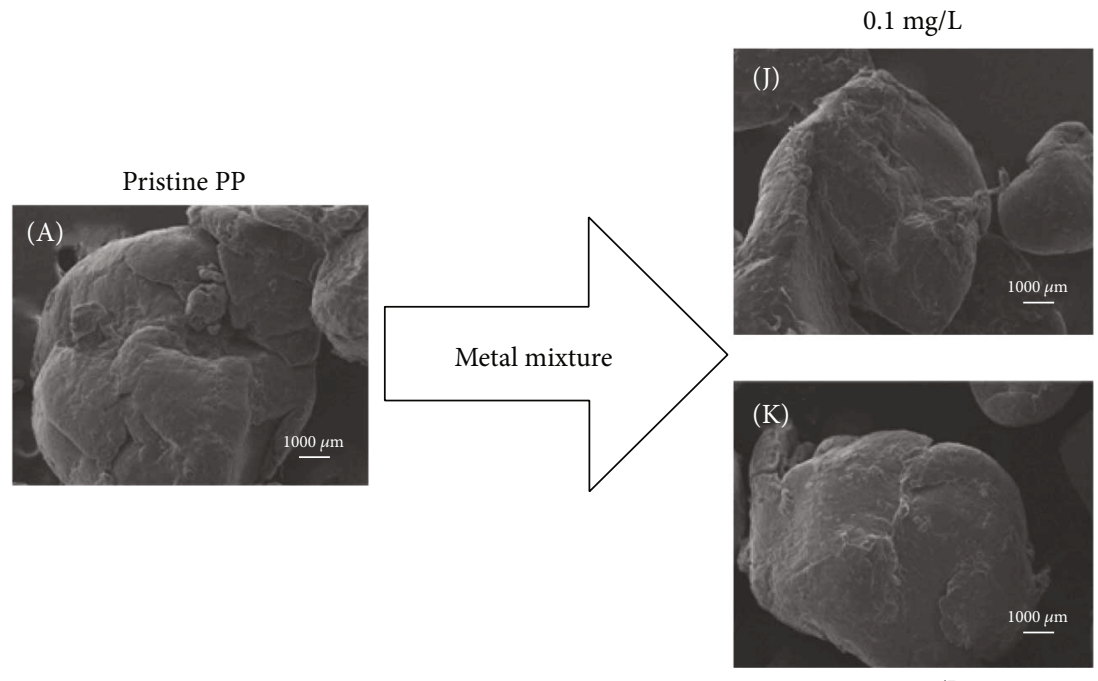

$0.1 \mathrm{mg} / \mathrm{L}$

FIGURE 8: Scanning electron microscopy of polypropylene adsorption of various heavy metals ( $V=20 \mathrm{~mL}$, temperature at $298 \mathrm{~K}, t=48 \mathrm{~h}$ ).

inhibited. Chen et al. studied the adsorption characteristics of $\mathrm{Pb}, \mathrm{Zn}, \mathrm{Cd}$, and $\mathrm{Cr}$ in the incineration process. They described several adsorption mechanisms: for metals with high volatility such as $\mathrm{Cd}$, physical molecular adsorption and particle growth are the main adsorption mechanisms; for heavy metals (medium to high volatility), such as $\mathrm{Pb}$, physical and chemical adsorption mechanisms are crucial; and for metals with low volatility, such as $\mathrm{Cu}$ and $\mathrm{Cr}$, chemical reactions are the main adsorption mechanism [50].
In this study, when the concentration of adsorbate is low, in the range of $0.1-0.3 \mathrm{mg} / \mathrm{L}$, the coexistence of various metals can promote the adsorption of $\mathrm{Pb}$ and $\mathrm{Cu}$, and then with an increase in the concentration of adsorbate, a coexistence system can inhibit the adsorption of microplastics. Overall, the adsorption rates of $\mathrm{Pb}, \mathrm{Cu}, \mathrm{Zn}$, and $\mathrm{Cd}$ are significantly different when the concentration of the adsorbate is the same, which indicates that there is competitive adsorption in the coexisting adsorption system [51]. In the 


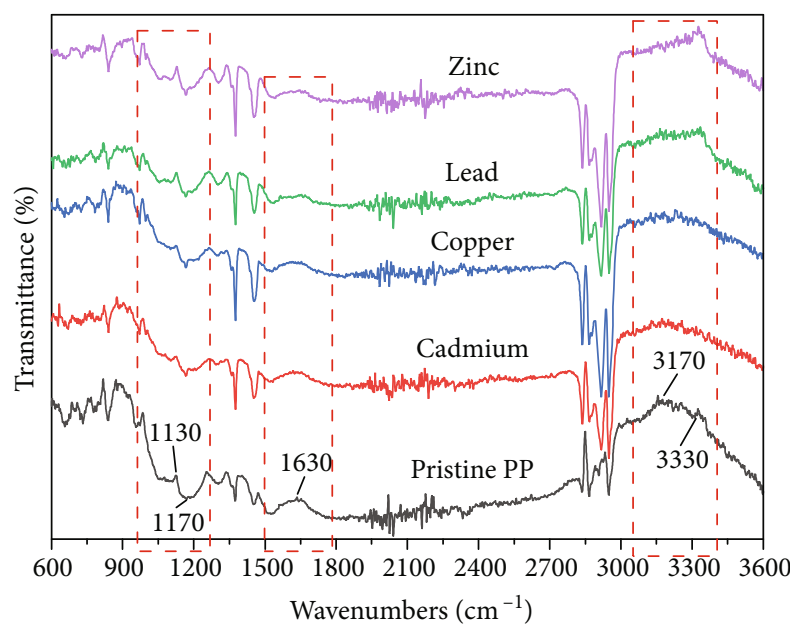

FIGURE 9: FTIR diagram of PP after adsorption of heavy metals with different concentrations $\left(C_{e}=0.7 \mathrm{mg} \cdot \mathrm{L}^{-1}, V=20 \mathrm{~mL}\right.$, temperature at $298 \mathrm{~K})$.

multicomponent adsorption of $\mathrm{Pb}, \mathrm{Cd}$, and $\mathrm{Ni}$ by microwave functionalized cellulose, Taha et al. mentioned that the coexistence of $\mathrm{Cd}$ and $\mathrm{Ni}$ can significantly slow down the absorption of $\mathrm{Pb}$, and $\mathrm{Pb}$ has the most obvious effect on the adsorption capacity [52], which is similar to the finding of our study. This may also be related to the adsorption mechanism of different heavy metals, and different adsorption mechanisms and reaction conditions will affect the adsorption of different metals by microplastics, showing different results.

\subsection{Characterization Analysis}

3.4.1. SEM Characterization Analysis. The surface morphology of PP was studied by SEM, and the results of adsorption of different heavy metals by PP are shown in Figure 7. At 100× magnification, 20-mesh polypropylene particles can be observed with irregular shapes and compact structures. As time passes, the surface of the PP becomes regular. With increasing of adsorption time, the surface voids of the PP decreased, probably because the absorption of heavy metals became regular. The 4 phenomenon of $\mathrm{PP}$ adsorption of $\mathrm{Zn}$ was very obvious. The results of the coexistence adsorption experiment are shown in Figure 8. The surface shape was more regular when the heavy metal concentration was $0.3 \mathrm{mg} / \mathrm{L}$ than when the heavy metal concentration was $0.1 \mathrm{mg} / \mathrm{L}$. This provides for a reference for us to better understand the adsorption properties of heavy metals to plastics.

3.4.2. FTIR Characterization Analysis. As shown in Figure 9, after adsorption of different heavy metals, the change trend of the FTIR absorption peak of PP was basically the same. As shown in Figure 10, the absorption peak strength of FTIR decreased significantly before and after the adsorption of various heavy metals by PP, but there was no significant change in the absorption peaks after the adsorption of different concentrations of heavy metals.

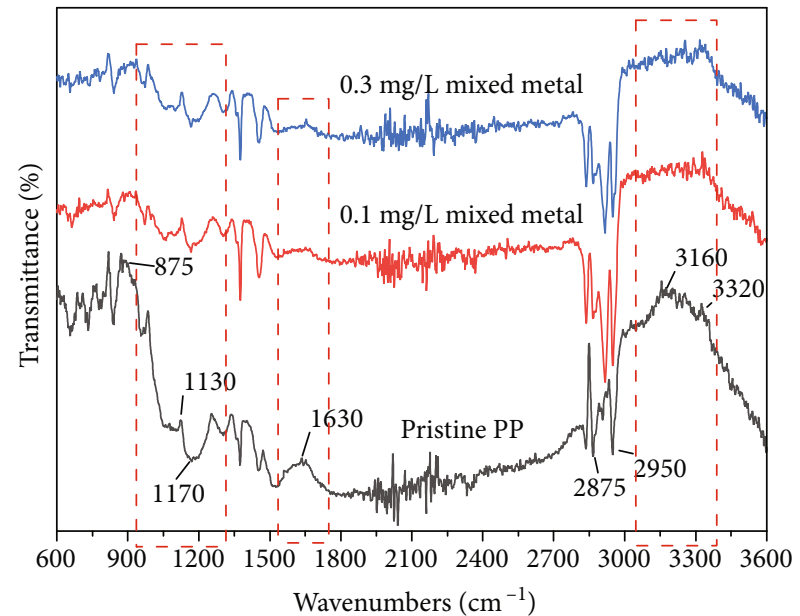

FIgURE 10: FTIR diagram of PP after adsorption of different kinds of heavy metals ( $V=20 \mathrm{~mL}$, temperature at $298 \mathrm{~K}, t=48 \mathrm{~h}$ ).

As shown in both Figures 9 and 10, the absorption band at $875 \mathrm{~cm}^{-1}$ can be attributed to the plane deformation of C$\mathrm{H}(-\mathrm{CH})$ monosubstituted benzene, and skeleton vibration is observed. The peaks were observed at 1130, 1375, and $1666 \mathrm{~cm}^{-1}$, which were caused by the tensile vibration of phenolic hydroxyl groups $(\mathrm{C}-\mathrm{OH})$ and carbonyl groups $(\mathrm{C}=\mathrm{O})$. The absorption band at $1630 \mathrm{~cm}^{-1}$ is attributed to aromatic carbon-carbon (C-C) skeleton vibrations.

3.4.3. XPS Characterization Analysis. Figure 11(a) shows the XPS characterization of microplastics before and after adsorbing heavy metals, making the positions of $\mathrm{C} 1 \mathrm{~s}, \mathrm{O} 1 \mathrm{~s}$, $\mathrm{Pb} 4 \mathrm{f}, \mathrm{Cd} 3 \mathrm{~d}, \mathrm{Zn} 2 \mathrm{p}$, and $\mathrm{Cu} 2 \mathrm{p}$ peaks. By fitting the peaks of high-resolution XPS spectra in the C1s and O1s regions, the chemical states of elements $\mathrm{C}$ and $\mathrm{O}$ can be identified (Figures 11(b) and 11(c)), and the peaks of different binding energy can also be seen corresponding to different groups from the graph. XPS analysis of the original microplastics PP has C1s peaks at $288.5 \mathrm{eV}, 286.0 \mathrm{eV}$, and $284.8 \mathrm{eV}$, representing $\mathrm{C}-\mathrm{H} / \mathrm{C}-\mathrm{C}, \mathrm{C}-\mathrm{O}-\mathrm{C}$, and $\mathrm{O}-\mathrm{C}=\mathrm{O}$, respectively. For the spectrum of $\mathrm{O} 1 \mathrm{~s}$, the peaks at junction of $531.4 \mathrm{eV}$ and $532.9 \mathrm{eV}$ are $\mathrm{C}-\mathrm{O}$ and $\mathrm{H}-\mathrm{O}-\mathrm{C}$, respectively. No other new peaks have been observed in the XPS spectrum, indicating that the mainly absorption of heavy metals of PP is physical adsorption. Lin et al. studied the XPS spectrum before and after microplastics adsorbing $\mathrm{Pb}$, indicating that there are no bonds between microplastics and $\mathrm{Pb}$ (II), and physical adsorption is the main driving force of microplastics adsorption [53].

As shown in the XPS high-resolution spectra of each heavy metal region in Figures 11(d)-11(f), peaks of Pb4f, $\mathrm{Cd} 3 \mathrm{~d}, \mathrm{Zn} 2 \mathrm{p}$, and Cu2p can be observed from the XPS survey of microplastics after adsorbing heavy metals, indicating the heavy metals were surely adsorbed on the surface of microplastics. But the results in the full spectrum map can not be obviously observed. It may be due to the heavy metals were mainly adsorbed into the interior of microplastics, so there is less surface adsorption [54]. 


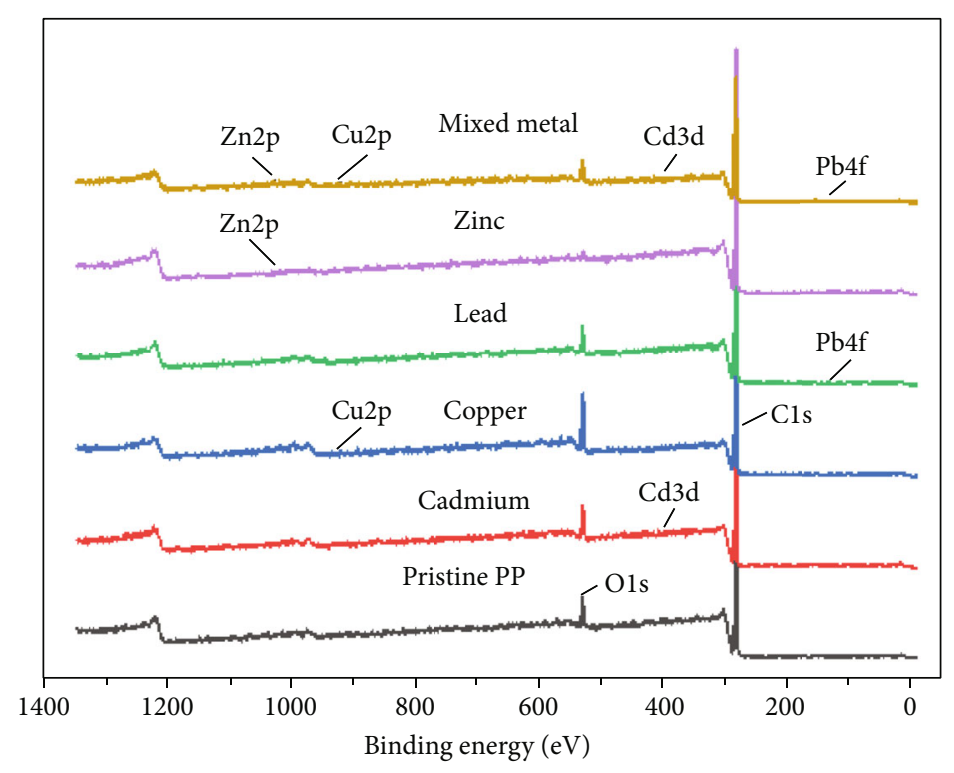

(a)

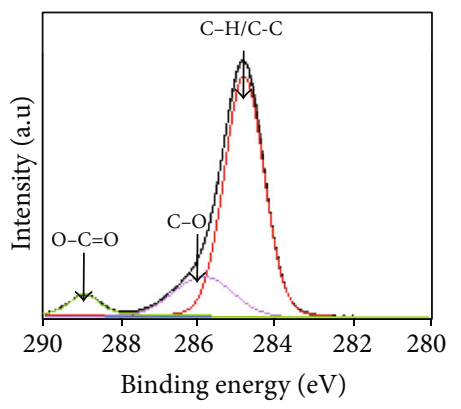

(b)

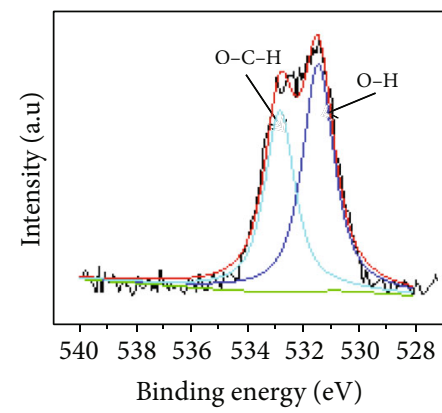

(c)

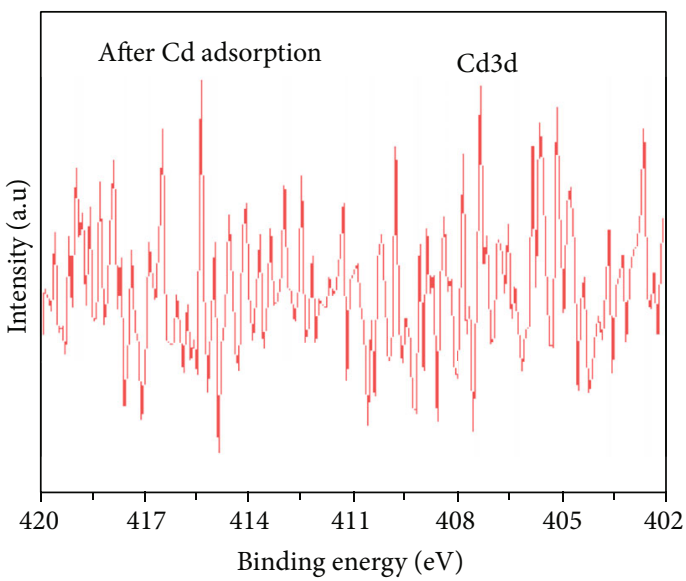

(e)

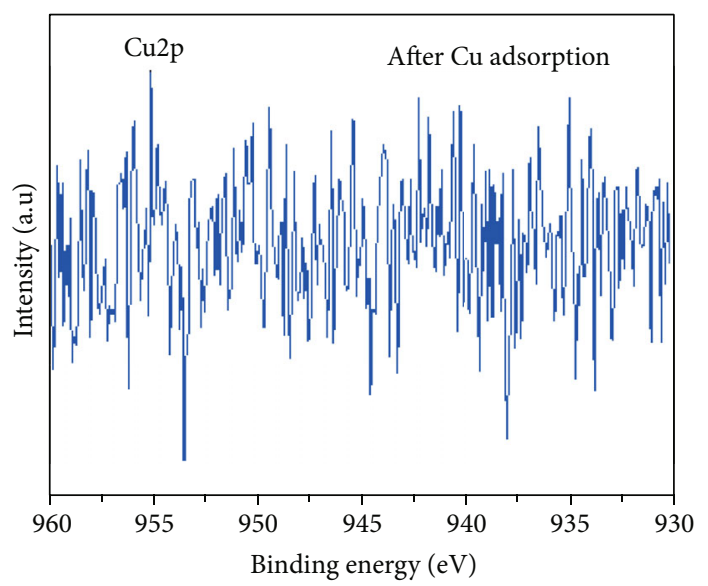

(d)

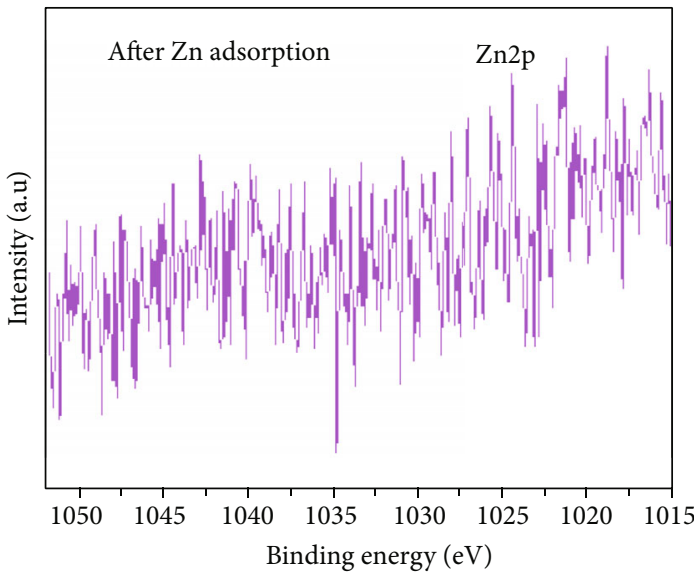

(f)

Figure 11: Continued. 


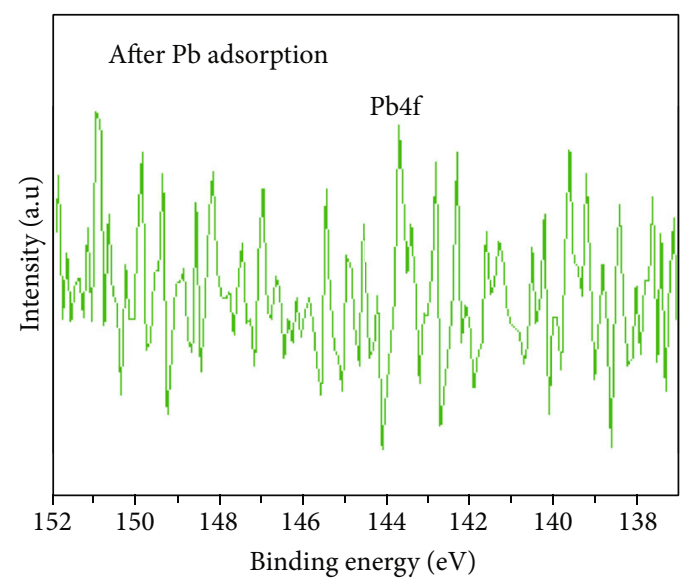

(g)

FIGURE 11: (a) XPS characterization before and after microplastics adsorption of heavy metals, (b) C1s spectrum of the original PP, (c) O1s spectrum of the original PP, (d) microplastic adsorption of $\mathrm{Cu}^{2+}$, (e) microplastic adsorption of $\mathrm{Cd}^{2+}$, (f) microplastic adsorption of $\mathrm{Zn}^{2+}$, and $(\mathrm{g})$ microplastic adsorption of $\mathrm{Pb}^{2+}(V=20 \mathrm{~mL}$, temperature at $298 \mathrm{~K}, t=48 \mathrm{~h})$.

\section{Conclusion}

The adsorption mechanism of 4 kinds of heavy metals $(\mathrm{Pb}$, $\mathrm{Cu}, \mathrm{CD}$, and $\mathrm{Zn}$ ) on PP over different time periods was studied to improve over understanding of the heavy metal adsorption characteristics of microplastics. Compared with previous studies, our kinetics model showed that different heavy metals have different adsorption characteristics, and the adsorption capacity of these 4 heavy metals is $\mathrm{Pb}^{2+}>-$ $\mathrm{Cu}^{2+}>\mathrm{Cd}^{2+}>\mathrm{Zn}^{2+}$. The adsorption is more consistent with the secondary kinetics and the adsorption has been proven to be multilayer and beneficial. In addition, we also studied the coexistence adsorption experiments of 4 kinds of heavy metals and found that there was competitive adsorption among the heavy metals, which was mainly related to the types and volatility of the adsorbates.

From the SEM characterization diagram, we can observe that the polypropylene particles before the adsorption of heavy metals are irregular in shape and have gaps on their surface. With the passage of adsorption time, the shape of PP tends to become regular. The FTIR characterization results showed that the change trend of the absorption peak of PP was basically the same before and after single adsorption of different heavy metals. When a variety of metals coexist for adsorption, the absorption peak strength of PP before and after adsorption slows down obviously at $900-1200 \mathrm{~cm}^{-1}$. In the future, we will focus on the adsorption characteristics and adsorption processes of other heavy metals.

\section{Data Availability}

The data used to support the findings of this study are available from the corresponding author upon reasonable request to953481783@qq.com.

\section{Additional Points}

Highlights. (1) The coexistent adsorption of four heavy metals $(\mathrm{Pb}, \mathrm{Cu}, \mathrm{Cd}$, and $\mathrm{Zn})$ by microplastics was consid- ered. (2) There was competitive adsorption between heavy metal adsorption, which was mainly related to the type and volatility of the adsorbed substance. (3) The adsorption characteristics depended on different types of heavy metals, and microplastics had the highest adsorption capacity for $\mathrm{Pb}$.

\section{Conflicts of Interest}

The authors declared no potential conflicts of interest with respect to the research, authorship, and/or publication of this article.

\section{Acknowledgments}

The authors extend their appreciation to the support by the Open Fund of State Key Laboratory of Simulation and Regulation of Water Cycle in River Basin, China Institute of Water Resources and Hydropower Research (IWHR-SKLKF201907), and the National Natural Science Foundation of China (Nos. 51878004 and 41402309).

\section{References}

[1] A. L. Andrady, "Microplastics in the marine environment," Marine Pollution Bulletin, vol. 62, no. 8, pp. 1596-1605, 2011.

[2] L. S. Fendall and M. A. Sewell, "Contributing to marine pollution by washing your face: microplastics in facial cleansers," Marine Pollution Bulletin, vol. 58, no. 8, pp. 1225-1228, 2009.

[3] D. Brennecke, B. Duarte, F. Paiva, I. Caçador, and J. CanningClode, "Microplastics as vector for heavy metal contamination from the marine environment," Estuarine Coastal and Shelf Science, vol. 178, pp. 189-195, 2016.

[4] A. Aguilera, F. Bautista, and A. Goguitchaichvili, "Health risk of heavy metals in street dust," Frontiers in Bioscience-Landmark, vol. 26, no. 2, pp. 327-345, 2021.

[5] J. Boucher and D. Friot, Primary microplastics in the oceans: a global evaluation of sources, Iucn Gland, Switzerland, 2017. 
[6] H. Du and J. Wang, "Characterization and environmental impacts of microplastics," Gondwana Research, vol. 98, pp. 63-75, 2021.

[7] E. Yousif and R. Haddad, "Photodegradation and photostabilization of polymers, especially polystyrene: review," Springer Plus, vol. 2, no. 1, pp. 1-32, 2013.

[8] F. Salvador Cesa, A. Turra, and J. Baruque-Ramos, "Synthetic fibers as microplastics in the marine environment: a review from textile perspective with a focus on domestic washings," Science of the Total Environment, vol. 598, pp. 1116-1129, 2017.

[9] M. Eriksen, L. Lebreton, H. S. Carson et al., "Plastic pollution in the world's oceans: more than 5 trillion plastic pieces weighing over 250, 000 tons afloat at sea," PLoS One, vol. 9, no. 12, article e111913, 2014.

[10] A. L. Andrady, "The plastic in microplastics: a review," Marine Pollution Bulletin, vol. 119, no. 1, pp. 12-22, 2017.

[11] F. Gao, J. Li, C. Sun et al., "Study on the capability and characteristics of heavy metals enriched on microplastics in marine environment," Marine Pollution Bulletin, vol. 144, pp. 61-67, 2019.

[12] Y. Zhou, X. Liu, and J. Wang, "Characterization of microplastics and the association of heavy metals with microplastics in suburban soil of central China," The Science of the Total Environment, vol. 694, article 133798, 2019.

[13] M. Mohsen, Q. Wang, L. Zhang, L. Sun, C. Lin, and H. Yang, "Heavy metals in sediment, microplastic and sea cucumber Apostichopus japonicus from farms in China," Marine Pollution Bulletin, vol. 143, pp. 42-49, 2019.

[14] G. Pellini, A. Gomiero, T. Fortibuoni et al., "Characterization of microplastic litter in the gastrointestinal tract of Solea solea from the Adriatic Sea," Environmental Pollution, vol. 234, pp. 943-952, 2018.

[15] M. Yazdani Foshtomi, S. Oryan, M. Taheri, K. Darvish Bastami, and M. A. Zahed, "Composition and abundance of microplastics in surface sediments and their interaction with sedimentary heavy metals, PAHs and TPH (total petroleum hydrocarbons)," Marine Pollution Bulletin, vol. 149, article 110655, 2019.

[16] L. A. Holmes, A. Turner, and R. C. Thompson, "Adsorption of trace metals to plastic resin pellets in the marine environment," Environmental Pollution, vol. 160, pp. 42-48, 2012.

[17] I. Acosta-Coley, D. Mendez-Cuadro, E. Rodriguez-Cavallo, J. de la Rosa, and J. Olivero-Verbel, "Trace elements in microplastics in Cartagena: a hotspot for plastic pollution at the Caribbean," Marine Pollution Bulletin, vol. 139, pp. 402-411, 2019.

[18] P. Wu, Z. Cai, H. Jin, and Y. Tang, "Adsorption mechanisms of five bisphenol analogues on PVC microplastics," Science of the Total Environment, vol. 650, pp. 671-678, 2019.

[19] A. A. Koelmans, A. Bakir, G. A. Burton, and C. R. Janssen, "Microplastic as a vector for chemicals in the aquatic environment. Critical review and model-supported re-interpretation of empirical studies," Environmental Science \& Technology, vol. 50, no. 7, pp. 3315-3326, 2016.

[20] K. Ashton, L. Holmes, and A. Turner, "Association of metals with plastic production pellets in the marine environment," Marine Pollution Bulletin, vol. 60, no. 11, pp. 2050-2055, 2010.

[21] M. Edelstein and M. Ben-Hur, "Heavy metals and metalloids: sources, risks and strategies to reduce their accumulation in horticultural crops," Scientia Horticulturae, vol. 234, pp. 431-444, 2018.

[22] M. Permata, A. Purwiyanto, and G. Diansyah, "Kandungan logam berat $\mathrm{Cu}$ (Tembaga) dan $\mathrm{Pb}$ (Timbal) pada air dan sedimen di Kawasan Industri Teluk Lampung, Provinsi Lampung," Journal of Tropical Marine Science, vol. 1, no. 1, pp. 7-14, 2018.

[23] A. Purwiyanto, "Distribution And Metal Adsorption of Lead $(\mathrm{Pb})$ In Estuary Banyuasin, South Sumatra (Distribusi dan adsorpsi logam timbal $(\mathrm{Pb})$ di Muara Sungai Banyuasin, Sumatera Selatan)," Indonesian Journal of Marine Sciences, vol. 20, no. 3, pp. 153-162, 2015.

[24] W. A. Eka Putri and A. I. Sunaryo Purwiyanto, "Cu and $\mathrm{Pb}$ concentrations in water column and plankton of downstream section of the Musi River," Jurnal Ilmu dan Teknologi Kelautan Tropis, vol. 8, no. 2, pp. 773-780, 2016.

[25] Y. Suteja and I. Dirgayusa, "Bioaccumulation and translocation of chromium on crabs and mangroves in Mati River estuary, Bali, Indonesia," AACL Bioflux, vol. 11, no. 2, pp. 469-475, 2018.

[26] M. R. Cordova and U. E. Hernawan, "Microplastics in Sumba waters, East Nusa Tenggara," IOP Conference, vol. 162, article 012023, 2018.

[27] M. R. Cordova, A. I. S. Purwiyanto, and Y. Suteja, “Abundance and characteristics of microplastics in the northern coastal waters of Surabaya, Indonesia," Marine Pollution Bulletin, vol. 142, pp. 183-188, 2019.

[28] M. R. Cordova and A. J. Wahyudi, "Microplastic in the deepsea sediment of southwestern sumatran waters.," Marine Research in Indonesia, vol. 41, no. 1, pp. 27-35, 2016.

[29] D. Falahudin, M. R. Cordova, X. Sun et al., "The first occurrence, spatial distribution and characteristics of microplastic particles in sediments from Banten Bay, Indonesia," The Science of the Total Environment, vol. 705, article 135304, 2020.

[30] E. S. Germanov, A. D. Marshall, I. G. Hendrawan et al., "Microplastics on the menu: plastics pollute Indonesian manta ray and whale shark feeding grounds," Frontiers in Marine Science, vol. 6, p. 679, 2019.

[31] R. Mao, M. Lang, X. Yu, R. Wu, X. Yang, and X. Guo, “Aging mechanism of microplastics with UV irradiation and its effects on the adsorption of heavy metals," Journal of Hazardous Materials, vol. 393, article 122515, 2020.

[32] A. Purwiyanto, Y. Suteja, Trisno et al., "Concentration and adsorption of $\mathrm{Pb}$ and $\mathrm{Cu}$ in microplastics: case study in aquatic environment," Marine Pollution Bulletin, vol. 158, article 111380, 2020.

[33] Q. Wang, Y. Zhang, X. Wangjin, Y. Wang, G. Meng, and Y. Chen, "The adsorption behavior of metals in aqueous solution by microplastics effected by UV radiation," Journal of Environmental Sciences, vol. 87, pp. 272-280, 2020.

[34] Z. Wei, C. Lzab, and H. Tian, "The mechanism for adsorption of $\mathrm{Cr}(\mathrm{VI})$ ions by $\mathrm{PE}$ microplastics in ternary system of natural water environment," Environmental Pollution, vol. 257, article 11344, 2020.

[35] C. Li, R. Busquets, and L. C. Campos, "Assessment of microplastics in freshwater systems: a review," The Science of the Total Environment, vol. 707, article 135578, 2020.

[36] A. A. Taha, M. A. Shreadah, A. M. Ahmed, and H. F. Heiba, "Multi-component adsorption of $\mathrm{Pb}(\mathrm{II}), \mathrm{Cd}(\mathrm{II})$, and $\mathrm{Ni}(\mathrm{II})$ onto Egyptian Na-activated bentonite; equilibrium, kinetics, thermodynamics, and application for seawater desalination," 
Journal of Environmental Chemical Engineering, vol. 4, no. 1, pp. 1166-1180, 2016.

[37] J. Yang, L. Cang, Q. Sun, G. Dong, S. T. Ata-Ul-Karim, and D. Zhou, "Effects of soil environmental factors and UV aging on Cu2+ adsorption on microplastics," Environmental Science and Pollution Research, vol. 26, no. 22, pp. 23027-23036, 2019.

[38] A. A. Ujile, Chemical engineering unit operations, synthesis and basic design calculations, Bomn Prints, Ibadan, Nigeria, 2014.

[39] H. Freundlich and W. Heller, "The Adsorption of cis- and trans-Azobenzene," Journal of the American Chemical Society, vol. 61, no. 8, pp. 2228-2230, 1939.

[40] H. K. Boparai, M. Joseph, and D. M. O'Carroll, "Kinetics and thermodynamics of cadmium ion removal by adsorption onto nano zerovalent iron particles," Journal of Hazardous Materials, vol. 186, no. 1, pp. 458-465, 2011.

[41] M. G. Ismail, N. W. Chan, H. A. Rahman, and N. A. Zakaria, "Freundlich isotherm equilibrium equastions in determining effectiveness a low cost absorbent to heavy metal removal in wastewater (Leachate) at Teluk Kitang landfill, Pengkalan Chepa, Kelantan, Malaysia," Journal of Geography and Earth Science, vol. 1, no. 1, pp. 1-8, 2013.

[42] T. S. Cleide, "Elucidation of mechanism involved in adsorption of $\mathrm{Pb}(\mathrm{II})$ onto lobeira fruit (Solanum lycocarpum) using Langmuir, Freundlich and Temkin isotherms," Microchemical Journal, vol. 137, pp. 348-354, 2018.

[43] D. Chen, T. Wang, Y. Ma et al., "Rapid characterization of heavy metals in single microplastics by laser induced breakdown spectroscopy," Science of the Total Environment, vol. 743, article 140850, 2020.

[44] V. Godoy, A. Martínez-Férez, M. Á. Martín-Lara, J. A. VellidoPérez, M. Calero, and G. Blázquez, "Microplastics as vectors of chromium and lead during dynamic simulation of the human gastrointestinal tract," Sustainability, vol. 12, no. 11, pp. 1-16, 2020.

[45] M. F. Lang, X. Q. Yu, J. H. Liu et al., "Fenton aging significantly affects the heavy metal adsorption capacity of polystyrene microplastics," Science of the Total Environment, vol. 722, article $137762,2020$.

[46] S. Tang, L. Lin, and X. Wang, " $\mathrm{Pb}$ (II) uptake onto nylon microplastics: interaction mechanism and adsorption performance," Journal of Hazardous Materials, vol. 386, article 121960, 2019.

[47] A. T. Ta and S. Babel, "Microplastic contamination on the lower Chao Phraya: abundance, characteristic and interaction with heavy metals," Chemosphere, vol. 257, article 127234, 2020.

[48] I. I. Fasfous, E. S. Radwan, and J. N. Dawoud, "Kinetics, equilibrium and thermodynamics of the sorption of tetrabromobisphenol A on multiwalled carbon nanotubes," Applied Surface Science, vol. 256, no. 23, pp. 7246-7252, 2010.

[49] B. Aaa, C. Kc, and W. D. Jie, "Adsorption of dissolved organic matter (DOM) on polystyrene microplastics in aquatic environments: kinetic, isotherm and site energy distribution analysis," Ecotoxicology and Environmental Safety, vol. 198, 2020.

[50] J. C. Chen, M. Y. Wey, and Z. S. Liu, "Adsorption mechanism of heavy metals on sorbents during incineration," Journal of Environmental Engineering, vol. 127, no. 1, pp. 63-69, 2001.

[51] B.-J. Ni, Q.-S. Huang, C. Wang, T. Y. Ni, J. Sun, and W. Wei, "Competitive adsorption of heavy metals in aqueous solution onto biochar derived from anaerobically digested sludge," Chemosphere, vol. 219, pp. 351-357, 2019.

[52] J. Qu, X. Tian, and Z. Jiang, "Multi -component adsorption of $\mathrm{Pb}(\mathrm{II}), \mathrm{Cd}(\mathrm{II})$ and $\mathrm{Ni}(\mathrm{II})$ onto microwave-functionalized cellulose: Kinetics, isotherms, thermodynamics, mechanisms and application for electroplating wastewater purification," Journal of Hazardous Materials, vol. 387, 2020.

[53] Z. Lin, Y. Hu, Y. Yuan, B. Hu, and B. Wang, "Comparative analysis of kinetics and mechanisms for $\mathrm{Pb}$ (II) sorption onto three kinds of microplastics," Ecotoxicology and Environmental Safety, vol. 208, article 111451, 2021.

[54] S. Tang, L. Lin, X. Wang, A. Yu, and X. Sun, "Interfacial interactions between collected nylon microplastics and three divalent metal ions $(\mathrm{Cu}(\mathrm{II}), \mathrm{Ni}(\mathrm{II}), \mathrm{Zn}(\mathrm{II}))$ in aqueous solutions," Journal of Hazardous Materials, vol. 403, article 123548, 2021. 